\title{
Assessment of Availability and Quality of Emergency Obstetric and Newborn Care Service in Southwestern Oromia, Ethiopia, 2017
}

\author{
Dejene Edosa \\ Department of Midwifery, College of Medicine and Health Sciences, Salale University, Fiche, Ethiopia \\ Correspondence should be addressed to Dejene Edosa; dejenedosa43@gmail.com
}

Received 22 February 2021; Revised 4 November 2021; Accepted 14 December 2021; Published 30 December 2021

Academic Editor: Sylvester C. Chima

Copyright (C) 2021 Dejene Edosa. This is an open access article distributed under the Creative Commons Attribution License, which permits unrestricted use, distribution, and reproduction in any medium, provided the original work is properly cited.

\begin{abstract}
Background. Emergency obstetrics and newborn care (EmONC) is an important lifesaving function which can avert the death of women facing obstetrics-related complications. It is a cost-effective, significant intervention to decrease maternal and neonatal morbidity and mortality in poor resource settings, including Ethiopia. Objective. The aim of this study was to assess the availability and quality of the EmONC services in southwestern Oromia, Ethiopia, in 2017. Methods. An institutional-based cross-sectional study was implemented from April to May 2017. Data were collected using checklists and questionnaires developed from different studies. Data were analyzed using EPI-info and exported to SPSS version 20 for further analysis. Each descriptive statistic was summarized using frequency, percentage, and tables for categorical variables. Results. Despite the fact that the overall coverage of fully functioning basic emergency obstetric and newborn care (BEmONC) facilities was greater than 5 per 500,000 people, nearly one-fourth (25.64\%) provided less than expected signal functions, indicating that these facilities were nonfunctional. There were only 0.24 comprehensive emergency obstetric and newborn care (CEmONC) facilities per 500,000 people. The result of this study also revealed that the quality of EmONC facilities in all health-care settings was poor. Conclusion and Recommendation. There were gaps in performance signal functions as well as the availability and quality of EmONC in the study area. Availability and quality of EmONC necessitate improvements through enhancing health-care providers' skills by training and mentoring as well as enabling facilities accessible for utilization of EmONC. Further research is needed to identify factors that could be barriers to the performance quality and coverage of EmONC services.
\end{abstract}

\section{Introduction}

1.1. Background. Maternal mortality is the most important health problem, particularly in sub-Saharan Africa, where more than half $(>50 \%)$ of all maternal deaths worldwide occur. Emergency obstetric and newborn care is a vital sequence of essential lifesaving tasks which can avert the death of women facing obstetric-related complications [1]. Emergency obstetric and newborn care (EmONC) is categorized as basic emergency obstetric and newborn care (BEmONC) and comprehensive emergency obstetric and newborn care (CEmONC). BEmONC can prevent up to $40 \%$ of intrapartum neonatal and maternal mortality [2].

BEmONC services consist of seven signal functions: administering parenteral antibiotics, uterotonic drugs, anticonvulsants, manual removal of the placenta, removal of products of retained tissue, performing assisted vaginal delivery, and performing neonatal resuscitation. CEmONC services necessitate two additional signal functions to BEmONC services: cesarean section and blood transfusion [3].

The Ethiopian final report of EmONC assessment revealed that, in spite of the government's target of $100 \%$ treatment of obstetric complications in health facilities, the met need for EmONC in 2016 was low (18\% in all facilities). Regionally, the met need for EmONC ranged from 3\% in Gambella to $83 \%$ in Addis Ababa. Most regions had a met need for EmONC of 33.3\% [4].

In Ethiopia, the availability and quality of EmONC are lower than the recommended levels, which contribute to the highest level of maternal mortality in the world. Ethiopia shares the challenges with many low-income countries of inadequate resources, weak infrastructure (especially roads), and a shortage of man power [5]. 
One of the key significant strategies encouraged to reduce maternal and neonatal mortality in low- and middle-income countries (LMIC) is the timely access to CEmONC, with the provision of BEmONC at the primary health-care level of a country's health system. To maintain the progression of monitoring this strategy, the availability of BEmONC services, the proportion of all live births taking place in health institutions, and the met need for EmONC are essential [6].

The study in the Tigray region indicated that the overall quality of BEmONC services from patients' perspective was poor. Clients scored lower quality rates on factors such as the availability of mandatory equipment, the lack of clean and functional bath and latrine facilities, the administration of analgesics during labor, and manual vacuum aspiration (MVA) [7].

The evaluation of EmONC in industrialized and developing countries was launched by the United Nation (UN) process indicators in 1997. These indicators include the number of hospitals providing emergency obstetric care per 500,000 people, the proportion of births and women with obstetric complications managed in hospitals, the cesarean section rate, and the case fatality rate [8].

A health center is a primary health-care setting that gives service to up to 25,000 people. Health-care providers working at a health center include midlevel health-care professionals, such as health officers, midwives, and nurses. The minimum recruitment at a health center set by the Ethiopian Standard Agency is two health officers, three midwives, and five nurses, together with specialized supporting personnel (e.g., laboratory and pharmacy technicians) [9].

The Averting Maternal Death and Disability Program (AMDD) and its UN partners continue to refine and improve the EmONC needs assessment. Today, the world increasingly recognizes that the value of needs assessments extends beyond EmONC and helps to improve many other parts of a country's health system [10].

Even though creditable progress has been made in availing the essential inputs and workforces, suboptimal quality BEmONC services remain mostly due to poor providers' competency, which should be a problem of urgent attention. One of the warning conditions for poor quality of health outcomes among women is the nonavailability and nonuse of modern health facilities by the majority of women in Ethiopia [11].

In southwestern Ethiopia, specifically the Ilu Abba Bor and Buno Bedelle zones, no study was conducted regarding the availability; quality, and utilization of EmONC services. Therefore, the aim of this study was to assess the availability and quality of EmONC services using the process indicators in Ilu Abba Bor and Buno Bedelle zones' health facilities.

Results from this study may help to further improve the quality of EmONC throughout the region. If Ethiopia and other nations in sub-Saharan Africa are successful in improving the quality of EmONC, women's utilization of these facilities might increase, and maternal and neonatal mortality are expected to be further reduced.

\section{Methods and Materials}

2.1. The Study Area, Period, and Design. A facility-based cross-sectional study was conducted in governmental health institutions in the Ilu Abba Bor and Buno Bedelle zones from April to May 2017. The capital towns of the zones are Mettu and Bedelle, located in southwestern Ethiopia at $600 \mathrm{~km}$ and $483 \mathrm{~km}$ from the capital, Addis Ababa, respectively. The 2007 census indicates the districts' total population was 1,271,609 and 829,663 (the total of 2,101,272 populations), respectively. There were three public hospitals, namely, Mettu Karl Referral Hospital, Darimu, and Bedelle Primary Hospitals, and 39 health centers expected to provide EmONC services in the district.

2.2. Population and Illegibility Criteria. All governmental hospitals \& health centers expected to give EmONC services in the district were included in the study. But private clinics were excluded because they were not expected to give EmONC services at this level.

2.3. Sample Size Determination. World Health Organization (WHO) recommends the use of all health facilities in the area if they are less than 100 in number for the evaluation of the EmONC performance [3]. Therefore, all health facilities (thirty-nine health centers and three hospitals) expected to provide EmONC services were included.

2.4. Data Collection Procedure and Data Quality Control. Data were collected by 4 data collectors using checklists and questionnaires developed from different literature. Each of the data collectors visited facilities and observed documents and records and interviewed key health officials at the facilities for clarification of any recorded data when required. Informed consent was taken from each health-care institution's key health officials by giving a detailed explanation about the objective, purpose, benefit, and importance of the study, and confidentiality of the information was maintained throughout data collection.

The tool was pretested at five health facilities in the Jimma zone (1 hospital and 4 health centers). Data quality was guaranteed using a pretested, structured checklist, and training was given for the data collectors for common understandings about the study, provision of full information, and appropriate documentation. For consistency and quality assurance, the data was collected from multiple registers/records from 1 April to 30 May 2017 and also simultaneously supervised and cross-checked.

2.5. Study Variables. The study variables used in this study are EmONC service availability, EmONC service quality, EmONC service utilization, roads, human resources, functional status of the EmONC facility, complicated obstetric cases, and maternal deaths. 
2.6. Data Processing and Analysis. Data analysis was done by using EPI-info version 7 and then exported to SPSS version 20 for analysis. After categorizing and defining variables, descriptive statistical tests were carried out for availability and quality of EmONC. Each descriptive statistic was summarized using frequency, percentage, and tables for categorical variables.

Calculations for the number of EmONC facilities per 500,000 people, population-based cesarean section rate, and direct obstetric case fatality rate (CFR) were done as follows [1]:

(i) Rate of CEmONC facilities per 500,000 people$=$ existing $\mathrm{CEmONC} /$ total population $\times 500,000$

(ii) Rate of BEmONC facilities per 500,000 people$=$ Existing BEmONC/total population $\times 500,000$

(iii) Population-based cesarean section rate $=$ number of CS performed in the last 12 months/expected deliveries in the catchment area with the same period $\times 100$

(iv) Case fatality rate (CFR) $=$ total number of maternal deaths from direct obstetric complications in the last 12 months preceding assessment $\times 100 / \mathrm{ex}^{-}$ pected deliveries in the catchment area with the same period

\subsection{Operational Definitions}

2.7.1. Availability of EmONC Services. These are the BEmONC and CEmONC services providing lifesaving obstetric procedures, including surgery. The minimum acceptable levels are as follows: there should be one facility providing fully functioning CEmONC, and five facilities providing fully functioning BEmONC for every 500,000 people [3].

2.7.2. Quality EmONC Services. Quality EmONC services are the degree to which the actual performance or achievement of the health service system corresponds to set standards.

2.7.3. Fully Functioning EmONC Facilities. These are the facilities that provide all the required signal functions.

2.7.4. Partially Functioning EmONC Facilities. Partially functioning EmONC facilities are those that are missing one or more signal functions.

Facilities that did not meet these criteria were classified as non-EmONC facilities.

Hospitals that had performed seven or eight signal functions were classified as partially functioning CEmONC facilities. Likewise, health centers that had provided five or six signal functions were also classified as partially functioning BEmONC facilities.

Facilities that did not meet these criteria were classified as non-EmONC facilities.

\section{Results}

3.1. General Information about the Facilities Expected to Provide EmONC in Southwestern Oromia, Ethiopia, in 2017. A total of 42 facilities were planned for the study, and all of them, 39 BEmONC facilities (health centers) and 3 EmONC facilities (hospitals), were included. Nearly quarter $(23.4 \%)$ of health facilities were more than 30 kilometers (10\%) away from a nearby hospital. The majority of the health facilities $35(83.3 \%)$ had car road access, and $7(16.7 \%)$ were remote from having car road access (see Table 1 ).

3.2. Functional Status of the Facility for BEmONC and CEmONC in Southwestern Oromia, Ethiopia, in 2017. The facility needed to have provided seven signal functions during the three months before the survey, to be said to give quality BEmONC services. To provide quality care for the CEmONC designation, a facility needed to have performed all nine signal functions.

As a result, the majority of facilities in this study, 23 (58.98\%), were providing all of the signal functions of BEmONC services (fully functioning), and only $6(15.38 \%)$ of BEmONC facilities were partially functioning, but nearly one-fourth, 10 (25.64\%), were providing less than expected signal functions, which can be said to be nonfunctional (see Table 2).

3.3. Availability of EmONC Facilities That Perform Signal Functions during the Last 3 Months in Southwestern Oromia, Ethiopia, in 2017. Ilu Abba Bor and Buno Bedelle zones, with a total population of $2,101,272$, required nearly 4 CEmONC facilities and $20 \mathrm{BEmONC}$ facilities. Even though BEmONC health facilities met the UN recommended criteria ( $>5$ per 500,000 people), only one hospital was fully functional for CEmONC services with a ratio of 0.24 CEmONC facilities per 500,000 people.

Administration of uterotonics was performed 100\% in health centers, manual removal of the placenta was performed $84.6 \%$, removal of retained products of tissue was performed $89.7 \%$, and assisted vaginal delivery was performed $92.3 \%$. Among hospitals, two of them (66.7\%) were not performing blood transfusions, and one (33\%) was not performing cesarean section, while administration of parenteral antibiotics, administration of uterotonics, administration of parenteral anticonvulsants, manual removal of the placenta, removal of the retained products of tissue, assisted vaginal delivery, and performing newborn resuscitation with bag and mask were the most performed signal functions among the assessed hospitals in the zones (see Tables 3 and 4).

3.4. Quality of EmONC Facilities That Perform Signal Functions At Least Once during the Last 3 Months in Southwestern Oromia, Ethiopia, in 2017. Good quality maternal health services are those which are readily reachable; safe, effective, acceptable to potential users and are staffed by technically competent people; provide prompt 
TABle 1: General Information about the facilities expected to provide EmONC in southwestern Oromia, Ethiopia, in 2017.

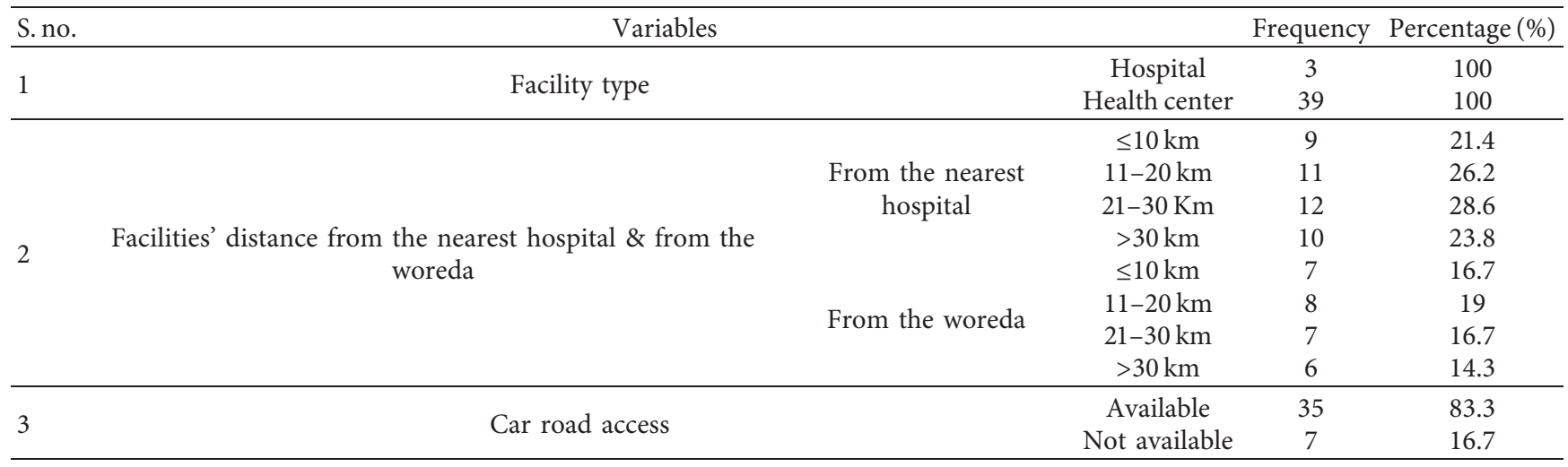

TABLE 2: Functional status of the facility for EmONC (BEmONC and CEmONC) in southwestern Oromia, Ethiopia, in 2017.

\begin{tabular}{|c|c|c|c|c|}
\hline S. no. & & Functional status & Facilities, $\mathrm{n}$ & $\%$ \\
\hline \multirow{4}{*}{1} & \multirow{4}{*}{ Functional status of BEmONC facilities } & 1. Fully functioning & 23 & $58.98 \%$ \\
\hline & & 2. Partially functioning & 6 & $15.38 \%$ \\
\hline & & 3. Not functioning & 10 & $25.64 \%$ \\
\hline & & Total & 39 & $100 \%$ \\
\hline \multirow{4}{*}{2} & \multirow{4}{*}{ Functional status of CEmONC facilities } & 1. Fully functioning & 1 & $33.3 \%$ \\
\hline & & 2. Partially functioning & 2 & $66.7 \%$ \\
\hline & & 3. Not functioning & 0 & 0 \\
\hline & & Total & 3 & $100 \%$ \\
\hline
\end{tabular}

comprehensive care; and provide continuity of care. Quality of EmONC service is determined by the proportion of the maternal death within the EmONC facility at a specified period admitted with direct obstetric complications at the same period. This is termed as the direct obstetric case fatality rate (CFR). The maximum acceptable level is less than $1 \%$ [1].

In this study, there were 230 mothers with direct obstetric complications recorded in the study facilities during the study period. The causes of these complications were found to be preeclampsia and eclampsia (12.2\%), hemorrhage $(21.3 \%)$, obstructed labor $(9.6 \%)$, postpartum sepsis $(12.6 \%)$, complicated abortion $(6.96 \%)$, ectopic pregnancy $(2.2 \%)$, and ruptured uterus $(2.6 \%)$.

The study also revealed that the maternal death occurred due to obstetric hemorrhage (postpartum hemorrhage) and hypertensive disorders (preeclampsia and eclampsia). Only one-third, 13 (33.3\%), health centers used partograph to monitor labor progress (Table 5).

3.5. Utilization of EmONC Facilities That Perform Signal Functions At Least Once during the Last 3 Months in Ilu Abba Bor District, Southwestern Oromia, Ethiopia, in 2017. The proportion of expected births that occurred in the assessed health facilities was $61 \%$ of all births in the study area. According to UN recommendation, the expected population need for EmONC is based on the assumption that $15 \%$ of expected deliveries will end up with complications.
In this study, out of total deliveries in the facility, $4.22 \%$ ended up with complications. Cesarean section performed was 251 (7.6\%) in two CEmONC facilities, and the population-based cesarean section rate (PBCSR) was $4.6 \%$. The case fatality rate (CFR) recorded in the past 3 months prior to assessment was $0.073 \%$ which was less than the acceptable level. Ninety-five mothers were referred to higher facilities (see Table 6).

3.6. Staff Profile of Health Facilities Working in the Delivery Room and Conducting Deliveries in Ilu Abba Bor and Buno Bedelle District, Southwestern Oromia, Ethiopia, in 2017. The minimum staffing level at a health center set by the Ethiopian Standard Agency (ESA) is two health officers, three midwives, and five nurses $[9,10]$.

This study identified that 165 different staffs were working in the delivery room of health facilities of the district during the study period.

The majority of staffs providing EmONC service were midwives, 104 (75 in the health centers and 29 in the hospitals). According to the ESA recommendation, the number of health staffs was not adequate to give EmONC services.

For example, the ESA recommends three midwives required for each 39 health center which mean 117 midwives for 39 health centers required. But, only 75 midwives were giving BEmONC services in the health centers during the study period (Table 7 ). 
TABLE 3: Basic emergency obstetric and newborn care (BEmONC) at least once during the last 3 months in southwestern Oromia, Ethiopia, in 2017.

\begin{tabular}{|c|c|c|c|c|c|c|c|c|}
\hline \multirow[b]{2}{*}{$\begin{array}{l}\text { S. } \\
\text { no. }\end{array}$} & \multirow[b]{2}{*}{$\begin{array}{c}\text { Names of } \\
\text { health centers }\end{array}$} & \multicolumn{7}{|c|}{ The basic emergency obstetric and newborn care (BEmONC) signal functions } \\
\hline & & $\begin{array}{l}\text { Parenteral } \\
\text { antibiotic }\end{array}$ & $\begin{array}{l}\text { Parenteral } \\
\text { oxytocin }\end{array}$ & $\begin{array}{c}\text { Parenteral } \\
\text { anticonvulsant }\end{array}$ & $\begin{array}{l}\text { Manual } \\
\text { removal of the } \\
\text { placenta }\end{array}$ & $\begin{array}{c}\text { Removal of } \\
\text { the retained } \\
\text { product }\end{array}$ & $\begin{array}{c}\text { Assisted } \\
\text { vaginal } \\
\text { delivery }\end{array}$ & $\begin{array}{l}\text { Perform newborn } \\
\text { resuscitation }\end{array}$ \\
\hline 1 & Mettu & $\checkmark$ & $\checkmark$ & $\checkmark$ & $\checkmark$ & $\checkmark$ & $\checkmark$ & $\checkmark$ \\
\hline 2 & Tulube & $\mathbf{X}$ & $\checkmark$ & $\mathbf{X}$ & $\checkmark$ & $\checkmark$ & $\mathbf{X}$ & $\checkmark$ \\
\hline 3 & Burusa & $\checkmark$ & $\checkmark$ & $\mathbf{X}$ & $\checkmark$ & $\checkmark$ & $\checkmark$ & $\checkmark$ \\
\hline 4 & Uka & $\checkmark$ & $\checkmark$ & $\checkmark$ & $\checkmark$ & $\checkmark$ & $\checkmark$ & $\checkmark$ \\
\hline 5 & Gore & $\checkmark$ & $\checkmark$ & $\checkmark$ & $\checkmark$ & $\checkmark$ & $\checkmark$ & $\mathbf{X}$ \\
\hline 6 & Gordomo & $\checkmark$ & $\checkmark$ & $\mathbf{X}$ & $\checkmark$ & $\mathbf{X}$ & $\checkmark$ & $\checkmark$ \\
\hline 7 & Sibo & $\checkmark$ & $\checkmark$ & $\checkmark$ & $\checkmark$ & $\checkmark$ & $\checkmark$ & $\checkmark$ \\
\hline 8 & Bure & $\checkmark$ & $\checkmark$ & $\checkmark$ & $\checkmark$ & $\checkmark$ & $\checkmark$ & $\checkmark$ \\
\hline 9 & Yayo & $\checkmark$ & $\checkmark$ & $\checkmark$ & $\checkmark$ & $\checkmark$ & $\checkmark$ & $\checkmark$ \\
\hline 10 & Sombo & $\checkmark$ & $\checkmark$ & $\checkmark$ & $\checkmark$ & $\checkmark$ & $\checkmark$ & $\checkmark$ \\
\hline 11 & Yembo & $\checkmark$ & $\checkmark$ & $\mathbf{X}$ & $\checkmark$ & $\mathbf{X}$ & $\checkmark$ & $\checkmark$ \\
\hline 12 & Hurumu & $\checkmark$ & $\checkmark$ & $\checkmark$ & $\checkmark$ & $\checkmark$ & $\checkmark$ & $\checkmark$ \\
\hline 13 & Alge & $\checkmark$ & $\checkmark$ & $\checkmark$ & $\checkmark$ & $\checkmark$ & $\checkmark$ & $\checkmark$ \\
\hline 14 & Supe & $\checkmark$ & $\checkmark$ & $\checkmark$ & $\checkmark$ & $\checkmark$ & $\mathbf{X}$ & $\checkmark$ \\
\hline 15 & Kame wato & $\mathbf{X}$ & $\checkmark$ & $\mathbf{X}$ & $\mathbf{X}$ & $\checkmark$ & $\checkmark$ & $\mathbf{X}$ \\
\hline 16 & Darimu & $\checkmark$ & $\checkmark$ & $\checkmark$ & $\checkmark$ & $\checkmark$ & $\checkmark$ & $\checkmark$ \\
\hline 17 & Becho & $\checkmark$ & $\checkmark$ & $\checkmark$ & $\checkmark$ & $\checkmark$ & $\checkmark$ & $\checkmark$ \\
\hline 18 & Sele nono & $\checkmark$ & $\checkmark$ & $\checkmark$ & $\checkmark$ & $\checkmark$ & $\checkmark$ & $\checkmark$ \\
\hline 19 & Doreni & $\checkmark$ & $\checkmark$ & $\checkmark$ & $\checkmark$ & $\checkmark$ & $\checkmark$ & $\checkmark$ \\
\hline 20 & Bedelle & $\checkmark$ & $\checkmark$ & $\checkmark$ & $\checkmark$ & $\checkmark$ & $\checkmark$ & $\checkmark$ \\
\hline 21 & Kolo siri & $\mathbf{X}$ & $\checkmark$ & $\mathbf{X}$ & $\mathbf{X}$ & $\checkmark$ & $\checkmark$ & $\mathbf{X}$ \\
\hline 22 & Gemeda & $\mathrm{X}$ & $\checkmark$ & $\mathrm{X}$ & $\checkmark$ & $\mathbf{X}$ & $\checkmark$ & $\checkmark$ \\
\hline 23 & Dega & $\checkmark$ & $\checkmark$ & $\checkmark$ & $\checkmark$ & $\checkmark$ & $\checkmark$ & $\checkmark$ \\
\hline 24 & Haro yajo & $\mathbf{X}$ & $\checkmark$ & $\mathbf{X}$ & $\mathbf{X}$ & $\checkmark$ & $\checkmark$ & $\mathbf{X}$ \\
\hline 25 & Meko & $\checkmark$ & $\checkmark$ & $\checkmark$ & $\checkmark$ & $\checkmark$ & $\checkmark$ & $\checkmark$ \\
\hline 26 & Gechi & $\checkmark$ & $\checkmark$ & $\checkmark$ & $\checkmark$ & $\checkmark$ & $\checkmark$ & $\checkmark$ \\
\hline 27 & Chara & $\mathbf{X}$ & $\checkmark$ & $\mathbf{X}$ & $\mathbf{X}$ & $\checkmark$ & $\checkmark$ & $\checkmark$ \\
\hline 28 & Dabo & $\checkmark$ & $\checkmark$ & $\checkmark$ & $\checkmark$ & $\checkmark$ & $\checkmark$ & $\checkmark$ \\
\hline 29 & Kone & $\mathbf{X}$ & $\checkmark$ & $\checkmark$ & $\checkmark$ & $\mathbf{X}$ & $\checkmark$ & $\mathbf{X}$ \\
\hline 30 & Yamfa & $\checkmark$ & $\checkmark$ & $\checkmark$ & $\checkmark$ & $\checkmark$ & $\checkmark$ & $\checkmark$ \\
\hline 31 & Yembero & $\checkmark$ & $\checkmark$ & $\mathbf{X}$ & $\mathbf{X}$ & $\checkmark$ & $\mathrm{X}$ & $\checkmark$ \\
\hline 32 & Chewaka & $\checkmark$ & $\checkmark$ & $\checkmark$ & $\checkmark$ & $\checkmark$ & $\checkmark$ & $\checkmark$ \\
\hline 33 & Dambi & $\checkmark$ & $\checkmark$ & $\checkmark$ & $\checkmark$ & $\checkmark$ & $\checkmark$ & $\checkmark$ \\
\hline 34 & Nopa & $\checkmark$ & $\checkmark$ & $\checkmark$ & $\checkmark$ & $\checkmark$ & $\checkmark$ & $\checkmark$ \\
\hline 35 & Chora & $\checkmark$ & $\checkmark$ & $\checkmark$ & $\checkmark$ & $\checkmark$ & $\checkmark$ & $\checkmark$ \\
\hline 36 & Abdela & $\checkmark$ & $\checkmark$ & $\checkmark$ & $\checkmark$ & $\checkmark$ & $\checkmark$ & $\checkmark$ \\
\hline 37 & Aba bora & $\checkmark$ & $\checkmark$ & $\checkmark$ & $\checkmark$ & $\checkmark$ & $\checkmark$ & $\mathbf{X}$ \\
\hline 38 & Gefo & $\mathbf{X}$ & $\checkmark$ & $\mathbf{X}$ & $\checkmark$ & $\checkmark$ & $\checkmark$ & $\mathrm{X}$ \\
\hline 39 & Kiltu & $\mathrm{X}$ & $\checkmark$ & $\mathrm{X}$ & $\mathbf{X}$ & $\checkmark$ & $\checkmark$ & $\mathrm{X}$ \\
\hline \multicolumn{2}{|c|}{ Total percentage } & $76.9 \%$ & $100 \%$ & $69.2 \%$ & $84.6 \%$ & $89.7 \%$ & $92.3 \%$ & $79.48 \%$ \\
\hline
\end{tabular}

$\checkmark$, service available; $\mathbf{X}$, service not available.

\section{Discussion}

This study has shown that among assessed facilities, the majority of them had availability of BEmONC as recommended by the UN. While CEmONC facilities were inadequate, the population-based cesarean section rate (PBCSR) was less than the recommended, and staffs for each health facility were inadequate. Maternal death occurred due to obstetric hemorrhage (postpartum hemorrhage) and hypertensive disorders (preeclampsia and eclampsia). According to the Ethiopian Standard Agency (ESA) recommendation, the number of health staffs was not adequate to give EmONC services.
Even though the overall coverage of fully functioning BEmONC facilities was $>5$ per 500,000 people, nearly onefourth $(25.64 \%)$ provided less than expected signal functions which can be said to be nonfunctional BEmONC facilities. The ratio of CEmONC facilities per 500,000 people was only 0.24 .

This is partly comparable with the study conducted in Ethiopia, Tanzania, and Cameroon which found that the availability of EmONC is below recommended levels. The study conducted in Tanzania reported that a total population of 214,454 required 1 CEmONC facility and 2 BEmONC facilities. In terms of the number of health facilities, the district has an excess number of CEmONC and BEmONC facilities, but in terms of functionality, the BEmONC 
TABLE 4: Comprehensive emergency obstetric and newborn care (CEmONC) at least once during the last 3 months in southwestern Oromia, Ethiopia, in 2017.

\begin{tabular}{|c|c|c|c|c|c|c|c|c|c|c|}
\hline \multirow[b]{2}{*}{ SNo. } & \multirow[b]{2}{*}{$\begin{array}{l}\text { Names of } \\
\text { hospitals }\end{array}$} & \multicolumn{9}{|c|}{ The comprehensive emergency obstetric and newborn care (CEmONC) signal functions } \\
\hline & & $\begin{array}{c}\text { Parenteral } \\
\text { antibiotic }\end{array}$ & $\begin{array}{l}\text { Parenteral } \\
\text { oxytocin }\end{array}$ & $\begin{array}{c}\text { Parenteral } \\
\text { anticonvulsant }\end{array}$ & $\begin{array}{l}\text { Manual } \\
\text { removal } \\
\text { of the } \\
\text { placenta }\end{array}$ & $\begin{array}{l}\text { Removal } \\
\text { of the } \\
\text { retained } \\
\text { product }\end{array}$ & $\begin{array}{c}\text { Assisted } \\
\text { vaginal } \\
\text { delivery }\end{array}$ & $\begin{array}{l}\text { Perform } \\
\text { newborn } \\
\text { resuscitation }\end{array}$ & $\begin{array}{c}\text { Blood } \\
\text { transfusion }\end{array}$ & $\begin{array}{c}\text { Cesarean } \\
\text { section }\end{array}$ \\
\hline & Mettu & & & & & & & & & \\
\hline 1 & $\begin{array}{c}\text { karl } \\
\text { hospital }\end{array}$ & $\checkmark$ & $\checkmark$ & $\checkmark$ & $\checkmark$ & $\checkmark$ & $\checkmark$ & $\checkmark$ & $\checkmark$ & $\checkmark$ \\
\hline 2 & $\begin{array}{l}\text { Bedelle } \\
\text { hospital }\end{array}$ & $\checkmark$ & $\checkmark$ & $\checkmark$ & $\checkmark$ & $\checkmark$ & $\checkmark$ & $\checkmark$ & $\mathbf{X}$ & $\checkmark$ \\
\hline 3 & $\begin{array}{l}\text { Darimu } \\
\text { hospital }\end{array}$ & $\checkmark$ & $\checkmark$ & $\checkmark$ & $\checkmark$ & $\checkmark$ & $\checkmark$ & $\checkmark$ & $\mathbf{X}$ & $\mathbf{X}$ \\
\hline & $\begin{array}{l}\text { Total } \\
\text { rcentage }\end{array}$ & $100 \%$ & $100 \%$ & $100 \%$ & $100 \%$ & $100 \%$ & $100 \%$ & $100 \%$ & $33.3 \%$ & $66.6 \%$ \\
\hline
\end{tabular}

$\checkmark$, service available; $\mathbf{X}$, service not available.

TABLE 5: Distribution of obstetric complications and the maternal outcome during the last 3 months in southwestern, Oromia, Ethiopia, in 2017.

\begin{tabular}{|c|c|c|c|c|c|c|c|c|c|}
\hline \multirow{2}{*}{ S. no. } & \multirow{2}{*}{ Complicated obstetric cases } & \multicolumn{4}{|c|}{ CEmONC-hospitals $(n=3)$} & \multicolumn{4}{|c|}{ BEmONC-health centers $(n=39)$} \\
\hline & & Managed & Referred & Death & Total & Managed & Referred & Death & Total \\
\hline 1 & Antepartum hemorrhage (APH) & $4(100 \%)$ & 0 & & $4(100 \%)$ & 0 & $17(100 \%)$ & & $17(100 \%)$ \\
\hline 2 & Postpartum hemorrhage (PPH) & $15(93.75 \%)$ & 0 & 1 & $16(100 \%)$ & $18(54.5 \%)$ & $14(42.2 \%)$ & 1 & $33(100 \%)$ \\
\hline 3 & Prolonged labor & $17(100 \%)$ & 0 & & $17(100 \%)$ & $3(8.1 \%)$ & $34(91.9 \%)$ & & $37(100 \%)$ \\
\hline 4 & Obstructed labor & $9(100 \%)$ & 0 & & $9(100 \%)$ & 0 & $13(100 \%)$ & & $13(100 \%)$ \\
\hline 5 & Postpartum sepsis & $17(100 \%)$ & 0 & & $17(100 \%)$ & $7(58.3 \%)$ & $5(41.7 \%)$ & & $12(100 \%)$ \\
\hline 6 & Complication of abortion & $7(100$ & 0 & & $77(100 \%)$ & $7(77.8 \%)$ & $2(22.2 \%)$ & & $9(100 \%)$ \\
\hline 7 & Preeclampsia/eclampsia & $13(72.2 \%)$ & $4(12.2 \%)$ & 1 & $18(100 \%)$ & $8(80 \%)$ & $1(10 \%)$ & 1 & $10(100 \%)$ \\
\hline 8 & Ectopic pregnancy & $3(60 \%)$ & $2(40 \%)$ & & $5(100 \%)$ & 0 & 0 & & 0 \\
\hline 9 & Ruptured uterus & $3(75 \%)$ & $1(25 \%)$ & & $4(100 \%)$ & 0 & $2(100 \%)$ & & $2(100 \%)$ \\
\hline & Total complication & $90(92.8 \%)$ & $7(7.2 \%)$ & 2 & $45(33.8 \%)$ & $88(66.2 \%)$ & & & 2 \\
\hline
\end{tabular}

TABle 6: Utilization of EmONC services in the past three months prior to the study in southwestern Oromia, Ethiopia, in 2017.

\begin{tabular}{|c|c|c|c|c|c|}
\hline S. no. & Types of services & Health center & Hospital & Total & $\%$ \\
\hline 1 & Catchment population & $2,101,272$ & & & \\
\hline 2 & Expected number of deliveries from the catchment population & 3317 & 2136 & 5453 & 100 \\
\hline 3 & The number of births that took place in the assessed facilities & 1891 & 1431 & 3322 & 61 \\
\hline 4 & The number of normal vaginal delivery & 1891 & 1180 & 3071 & 92.4 \\
\hline 5 & Cesarean section performed & NA & 251 & 251 & 7.6 \\
\hline 6 & Case fatality rate (CFR) & 2 & 2 & 4 & 0.073 \\
\hline 7 & The number of stillbirths & 8 & 63 & 71 & 2.14 \\
\hline 8 & The number of early neonatal death & 4 & 11 & 15 & 0.45 \\
\hline 9 & Partograph usage & 10 & 3 & 13 & 31 \\
\hline
\end{tabular}

TABLE 7: Staff available in assessed facilities and conducting delivery services in southwestern Oromia, Ethiopia, in 2017.

\begin{tabular}{|c|c|c|c|c|c|}
\hline S. no. & Health-care workers participated in EmONC & Health centers & Hospitals & Total & $\%$ \\
\hline 1 & Midwives & 75 & 29 & 104 & 55.6 \\
\hline 2 & Nurses & 7 & 16 & 23 & 12.3 \\
\hline 3 & Public health officers & 31 & 3 & 34 & 18.2 \\
\hline 4 & General practitioners (GPs) & - & 19 & 19 & 10.2 \\
\hline 5 & Integrated emergency obstetrics and surgery specialists (IEOSs) & - & 4 & 4 & 2.1 \\
\hline \multirow[t]{2}{*}{6} & Gynecologists and obstetrician & - & 3 & 3 & 1.6 \\
\hline & Total & 113 & 74 & 187 & 100 \\
\hline
\end{tabular}


facilities were limited. The study conducted in Cameroon showed inadequate EmONC facilities (2.2 BEmONC facilities per 500,000 people and 0.6 CEmONC facilities per 500,000 people) $[5,12,13]$.

However, the findings of the studies conducted in the Dire Dawa town, Ethiopia, and Ibadan-Ibarapa zone, Nigeria, were in line with this study which revealed the BEmONC facility ratio met the minimum standard, and the CEmONC facility is not adequate to the size of the population $[1,14]$.

Regarding utilization of EmONC, the study showed that the proportion of expected births that occurred in the assessed health facilities was $61 \%$ which was higher than the recommended level by the UN. Out of total deliveries in the facility, $7 \%$ ended up with complications. In CEmONC facilities of the study area, the population-based $\mathrm{C} / \mathrm{S}$ rate was $4.6 \%$ that was less than the recommended level.

This is also in agreement with the study conducted in Lusaka District, Zambia, which indicated that the observed proportion of expected births taking place in the facilities was $65.3 \%$ and cesarean section (C/S) was $7 \%$ which have met the UN recommended levels. Public and private health facilities performed $4 \%$ elective and emergency cesarean sections that was below the recommended level [15].

Another result of this study revealed that the quality of EmONC facilities in all health-care setting was poor. The quality of services provided by health facilities is measured by calculating the case fatality rate. There were 230 mothers with direct obstetric complications recorded in the study facilities due to different causes.

Another finding of this study also indicated that maternal death occurred due to obstetric hemorrhage (postpartum hemorrhage) and hypertensive disorders (preeclampsia and eclampsia). The maternal death rate recorded in the past 3 months prior to assessment was $0.12 \%$. This is in line with a study conducted in Addigrat town, Tigrai, which revealed that the overall quality of BEmONC services from patients' perspective was poor. Clients noted lower quality services during receiving BEmONC [7].

Trained and competent health-care providers are required for the provision of quality services. But, in this study, there was no fair distribution of health-care providers in which many of the providers were being at the hospital that most of them are in urban, and health centers in rural mostly have the lower and least trained personnel. This corresponds with the study conducted in Tanzania which showed that the human resource challenge has been reported by the lower facilities which are mostly in rural tend to have the least trained personnel compared to hospitals which are mostly in urban areas [16].

\section{Conclusion}

This study has shown that the BEmONC facility ratio met the minimum standard for the population size while the CEmONC facility ratio was not adequate. The case fatality rate was lower than acceptable by the UN standard. In CEmONC facilities of the study area, the population-based $\mathrm{C} / \mathrm{S}$ rate was lower than the recommended, $4.6 \%$. Obstetric hemorrhage (antepartum and postpartum hemorrhage) and hypertensive disorders (preeclampsia and eclampsia) were the leading cause of maternal death and the most frequent obstetric complications in district health facilities.

5.1. Recommendation. Hospitals should improve to give CEmONC services, and health centers had to be upgraded to fully functioning BEmONC facilities. Quality improvement of EmONC services need to be offered through enabling facilities for accessible utilization of EmONC facilities, increasing supplies for health facilities, improving providers' skills in EmNOC through BEmONC and CEmONC training because many obstetric complications such as hypertensive disorders and obstetric hemorrhage cause maternal death. Further research is needed to identify factors that could be barriers to the performance of signal functions and ultimately the functionality, quality, and coverage of EmONC services in the study area.

\section{Abbreviations}

APH: Antepartum hemorrhage

BEmONC: Basic emergency obstetric and neonatal care

C/S: $\quad$ Cesarean section

CFR: Case fatality rate

CEmONC: Comprehensive emergency obstetric and neonatal care

EmONC: Emergency obstetric and neonatal care

ESA: Ethiopian Standard Agency

$\mathrm{km}$ : Kilometer

MVA: $\quad$ Manual vacuum aspiration

PPH: $\quad$ Postpartum hemorrhage

UN: $\quad$ United Nations

WHO: World Health Organization.

\section{Data Availability}

The data used or analyzed throughout the current study will be obtained upon request from the corresponding author.

\section{Ethical Approval}

Ethical approval for the study was given by the Ethio-Canada $\mathrm{MCH}$ project and Mettu University Research Ethical Review Committee, and permission for the study was taken from the relevant institutions.

\section{Consent}

The data were collected after fully informed written consent was taken, and the confidentiality of the information was maintained throughout data collection.

\section{Conflicts of Interest}

There are no conflicts of interest. 


\section{Acknowledgments}

The author would like to thank the Ethio-Canada $\mathrm{MCH}$ Project and Mettu University for their support.

\section{References}

[1] Teshome and Eticha, "Availability and quality of emergency obstetric and newborn care service in dire dawa," Journal of Women's Health Care, vol. 5, no. 5, p. 5, 2016.

[2] A. H. Mirkuzie, M. M. Sisay, A. T. Reta, and M. M. Bedane, "Current evidence on basic emergency obstetric and newborn care services in Addis Ababa, Ethiopia; a cross sectional study," BMC Pregnancy and Childbirth, vol. 14, no. 1, p. 354, 2014, https://www.biomedcentral.com/1471-2393/14/354.

[3] A. Defar, Baseline Evaluation of Maternal and Newborn Health Care Services in 25 Selected Woredas, Federal Minster of Health (FMoH) Health System Research Directorate, Ethiopian Health and Nutrition Research Institute (EHNRI), Addis Ababa, Ethiopia, 2013.

[4] T. Taddele, Ethiopian Emergency Obstetric and Newborn Care (EmONC) Assessment Final Report, Federal Ministry of Health, Ethiopia Averting Maternal Death and Disability (AMDD), Columbia University, New York, NY, USA, 2017.

[5] K. Admasu, A. Haile-Mariam, and P. Bailey, "Indicators for availability, utilization, and quality of emergency obstetric care in Ethiopia, 2008," International Journal of Gynecology \& Obstetrics, vol. 115, no. 1, pp. 101-105, 2011.

[6] G. T. Tiruneh, A. M. Karim, B. I. Avan et al., "The effect of implementation strength of basic emergency obstetric and newborn care (BEmONC) on facility deliveries and the met need for BEmONC at the primary health care level in Ethiopia," BMC Pregnancy and Childbirth, vol. 18, no. 1, p. 123, 2018.

[7] B. Birhane, Quality of Basic Emergency Obstetric and Newborn Care (BEmONC) Services from Patients' Perspective in Adigrat Town, Eastern Zone of Tigray, Ethiopia. 2017: A Cross Sectional Studyjournal List BMC Pregnancy Childbirth, vol. 19, 2019 PMC654360.

[8] M. Girma, Assessment of Availabiltiy and Utlization of Emergency Obstetric Care Services in Gamo Goffa Zone, Snnpr, Ethiopia, University of Gonder and Addis Continental Institute of Public Health May, 2011.

[9] M. Windsma, T. Vermeiden, F. Braat et al., "Emergency obstetric care provision in Southern Ethiopia: a facility-based survey," BMJ Open, vol. 7, no. 11, Article ID e018459, 2017.

[10] Ethiopian Public Health Institute, Assessments for Emergency Obstetric and Newborn Care (EmONC), Ethiopia Federal Ministry of Ethiopia Averting Maternal Death and Disability (AMDD), Columbia University, New York, NY, USA, 2016.

[11] A. S. Miltenburg, "Assessing emergency obstetric and newborn care: can performance indicators capture health system weaknesses?" BMC Pregnancy and Childbirth, vol. 17, no. 92, 2017.

[12] R. Muhammad Bakari, "Assessment of availability, utilization and quality of emergency obstetric care in 2014 at Hai district, northern Tanzania," Journal of Gynecology and Obstetrics, vol. 3, no. 3, pp. 43-48, 2015.

[13] Kadia, "Evaluation of emergency obstetric and neonatal care services in kumba health district, Southwest region, Cameroon (2011-2014): a before-after study BMC pregnancy and childbirth," vol. 20, p. 95, 2020.

[14] E. A. Bamgboye, A. O. Adebiyi, and A. A. Fatiregun, "Assessment of emergency obstetric care services in ibadan- ibarapa health zone, Oyo state, Nigeria," African Journal of Reproductive Health, vol. 20, no. 1, pp. 88-97, 2016.

[15] T. Tembo, G. Chongwe, B. Vwalika, and L. Sitali, "Signal functions for emergency obstetric care as an intervention for reducing maternal mortality: a survey of public and private health facilities in Lusaka district, Zambia," BMC Pregnancy and Childbirth, vol. 17, no. 1, p. 288, 2017.

[16] F. Serbanescu, Health Facility Assessment of Emergency Obstetric \& Neonatal Care Services (EmONC) in Kigoma Region, Tanzania: Selected Findings, Kigoma Region and Tanzania, 2010. 